\title{
O espaço da cultura em Minas Gerais: aglomerações territoriais, desenvolvimento socioeconômico e concentração regional entre 1920 e 2010
}

The space of culture in Minas Gerais: territorial clusters, socioeconomics development and regional concentration between 1920 and 2010

\author{
Cleber Dias ${ }^{(1)}$ \\ Ana Flávia Machado (2) \\ Vinicius Morais Silveira Hosken ${ }^{(3)}$ \\ (1) Universidade Federal de Minas Gerais \\ (2) Universidade Federal de Minas Gerais \\ (3) Universidade Federal de Minas Gerais
}

\section{Abstract}

This paper aims to analyze the temporal evolution of cultural clusters in Minas Gerais. To this end, the cluster method was applied to the data from the 1920 State Yearbook, the Profile of Municipalities in 2006 and the Demographic Census in 2010, using variables related to socioeconomic development (literate population and home access to sewage) and culture (number of movie and theaters), taking the municipality by unit of analysis. As in 1920 the state of Minas Gerais had 178 municipalities and 853 in 2010, the geographic distribution of 2010 was made compatible with that of 1920 . The application of the method generated four clusters in each year, which showed almost through a century an association between indicators of opportunities for access to cultural consumption to higher percentages of the literate population and the highest rates of households with access to the sewerage.

\section{Keywords}

culture, development, clusters, Minas Gerais.

JEL Codes Z1, O1, C38.

\section{Resumo}

Este artigo pretende mapear e avaliar a evolução temporal de aglomerados culturais em Minas Gerais. Para tanto, aplicou-se o método de aglomerados aos dados do Anuário Estadual de 1920, do Perfil de Municípios em 2006 e do Censo Demográfico em 2010, utilizando de variáveis relativas a desenvolvimento socioeconômico (população alfabetizada e acesso domiciliar a rede de esgoto) e à cultura (número de salas de cinema e teatros), tendo-se por unidade de análise o município. Como em 1920, o estado mineiro contava com 178 municípios e, em 2010, 853, foi feita uma compatibilização da distribuição geográfica de 2010 espelhando-se na de 1920. A aplicação do método gerou quatro clusters em cada ano, que evidenciaram, ao longo de quase um século, associação entre indicadores de oportunidades de acesso ao consumo cultural a maiores percentuais da população alfabetizada e aos maiores indices de domicílios com acesso a rede de esgoto.

\section{Palavras-chave}

cultura, desenvolvimento, aglomerados, Minas Gerais.

Códigos JEL Z1, O1, C38. 


\section{Introdução}

As amenidades urbanas e a qualidade de vida são fatores importantes para o desenvolvimento de atividades artístico-culturais. Lazzeretti, Boix e Capone (2013) argumentam que o patrimônio tangível (prédio, monumentos, pinturas e artefatos históricos) deriva das tradições, de costumes, da língua, do modo de vida, ou seja, do patrimônio intangível de um determinado território. Essa sinergia atribui ao território um papel importante na definição dos aglomerados. O segundo fenômeno que torna o território uma categoria de análise quando se está tratando de atividades culturais são as economias de aglomeração. Tais economias estão associadas às vantagens em custos ou qualidade graças à concentração espacial de recursos produtivos e atores (população, firmas, instituições e outros agentes coletivos). Não é diferente no caso da cultura, pois também são afetadas por economias de aglomeração, as quais basicamente agem como forças centrípetas, promovendo a incubação e atração de outras atividades culturais em lugares com características específicas (economias de localização) ou em grandes cidades metropolitanas (economias de urbanização) (Chapain; De Propris, 2009).

As economias de localização ocorrem graças à concentração de diversas firmas de características semelhantes em localizações especificas. Desse ponto de vista, as atividades culturais concentram-se para tirar vantagem da existência de um mercado de trabalho competente, da existência de fornecedores locais especializados em outras partes do setor, e para se beneficiar de repercussões de conhecimento local. Os limites das firmas se tornam porosos e o fluxo de ideias, informações técnicas, signos extrapolam o local de trabalho, alcançando outros estabelecimentos e vivências informais de trabalho. Com o crescimento da importância dos contextos locais, espaços públicos são capazes de absorver, transformar e recombinar antigas e novas experiências com novos e diversos recursos e capacidades (Lazzeretti, 2013).

Jacobs (2011) desenvolve o conceito de economias de urbanização como uma derivada das economias de aglomeração. Neste caso, para além das atividades relacionadas, há concentração de outras, como as artísticas-culturais, porque essas vão se apropriar dos ganhos de escala tanto na produção quanto no consumo proveniente de maior densidade e diversidade populacional. Empresas dedicadas à produção de bens e serviços di- 
ferenciados por conteúdos criativos e culturais, do mesmo modo, também se concentram territorialmente para tirar vantagens da disponibilidade de trabalhadores qualificados e de fornecedores locais especializados (Santagata, 2006). Assim, ao contrário das firmas industriais verticais, fechadas em seus processos de trabalho coordenados por regras, normas e segredos tecnológicos, as atividades culturais ganham com a concentração em determinado espaço físico, mas também ampliam sua participação por meio da fruição de ideias, de técnicas, de informações e de pessoas no ambiente mais pulverizado.

Logo, a reunião de amenidades urbanas e de equipamentos culturais pode representar vantagens comparativas não apenas em termos de produção e de consumo cultural, mas também em termos econômicos mais gerais, ampliando, assim, ao menos em tese, as oportunidades de desenvolvimento. Não por acaso, as artes e a cultura têm sido reiteradamente apontadas como vetores relevantes para a geração de riquezas e expansão do produto nacional.

A exemplo do feito em Machado, Simões e Diniz (2013), pretende-se neste trabalho mapear e avaliar a evolução no tempo desses aglomerados culturais em Minas Gerais - um dos 27 estados do Brasil - situado na Região Sudeste do país. Com esse propósito, recorre-se às informações da MUNIC e do Anuário Estatístico de 1920 e do Censo Demográfico de 2010. Para tanto, utilizaremos informações referentes à taxa de alfabetização, ao esgotamento sanitário, ao número de cinemas e de teatros em Minas Gerais, conforme detalhamentos e justificativas na seção 3 deste artigo (Aspectos metodológicos: a compatibilização territorial e a técnica de cluster).

A aplicação do método de aglomeração ao conjunto desses dados possibilita classificar seus elementos em grupos restritos homogêneos internamente, permitindo gerar estruturas agregadas significativas e desenvolver tipologias analíticas, tais como a de territórios. Desse modo, pretende-se não somente mapear esses territórios mineiros em dois pontos no tempo, quais sejam, os anos de 1920 e 2010, como também analisar as modificações ocorridas (ou não) na distribuição dos aglomerados no espaço à luz da história econômica da cultura em Minas Gerais.

Esse último objetivo é relevante e se trata de uma contribuição para a literatura, posto que, como salientado por Blaug (2001), são poucos os estudos da área que versam sobre a história econômica cultural e, no caso 
brasileiro, é praticamente inexistente a aplicação de métodos de clustering para tratar de um mesmo território em um período de quase um século nos aspectos da cultura. Nesse sentido, o texto se divide em quatro seções, incluindo essa. Na segunda, um pouco da história cultural de Minas Gerais é contado. Em seguida, na terceira, apresentamos a compatibilização territorial entre os dois períodos analisados e aspectos referentes à metodologia de cluster e variáveis selecionadas. Na quarta, discutimos os achados. E, por fim, esboçamos algumas considerações.

\section{Panorama da história da cultura de Minas Gerais}

A vida cultural em Minas Gerais em princípios do século XX ainda era em grande medida marcada pela tradição do mundo rural, em vez da modernidade dos grandes centros urbanos. Não por acaso, oposições entre tradição e modernidade, entre rural e urbano, pareciam um dos traços mais marcantes do imaginário intelectual de Minas Gerais nesse período - tal como em outras cidades brasileiras e mesmo latino-americanas (cf. Rama, 2015; Romero, 2004; Cabrejo, 2012).

Nesses termos, a vida nas cidades era idealizada como o lugar do progresso e da sofisticação dos costumes, em detrimento ao atraso e arcaísmo da vida nos campos. De acordo com o léxico dessas representações, grandes cidades eram os locais onde a oferta comercial de oportunidades de consumo cultural eram mais frequentes e regulares. Mais que isso, tais oportunidades mais abundantes de acesso a um mercado de entretenimento eram parte fundamental da própria modernidade das cidades, na mesma medida em que a ausência de tudo isso, em sentido contrário, era tida como em grande medida responsável pelo atraso de áreas rurais. Esta é uma das razões pelas quais grupos das elites de diferentes cidades de Minas Gerais engajaram-se, às vezes muito ativamente, na reivindicação de ampliação das estruturas de lazer urbano como parte de uma estratégia para impulsionar o progresso regional. A inauguração de um teatro, de um cinema, de um café, de uma praça ou de um clube de esportes era vista e apresentada como índice de progresso. Em 1907, por exemplo, um cronista anônimo do jornal Gazeta de Minas, publicado na cidade de Oliveira, no oeste de Minas Gerais, sintetizou essa escala de valores, em palavras que de outro modo foram repetidas em várias cidades da região: "os passeios 
públicos, os teatros, os cafés são elementos da vitalidade de um povo. Cidade sem estes complementos é uma roça" (Amaral; Dias, 2019, p. 84).

Contrariando esses desejos e expectativas, as sociabilidades cotidianas em Minas Gerais em princípios do século XX ainda estavam fortemente submetidas ao ritmo da natureza e aos costumes comunitários. $O$ trabalho no campo e os costumes culturais típicos de uma comunidade camponesa ainda eram as estruturas fundamentais que regulavam o cotidiano da maioria da população. No mesmo sentido, festas religiosas em comemoração às datas do calendário litúrgico do catolicismo apareciam como uma das mais constantes oportunidades de lazer para a população de Minas Gerais nesse período (Perez, 2009). Essas festas estavam entre as principais ocasiões a interromper as obrigações laborais, dando lugar a quermesses, leilões, bailes, apresentações teatrais e várias outras formas de divertimentos que compunham parte dos rituais religiosos. Nessa época, festas religiosas imbricavam dimensões sagradas e profanas, o que aprofundava $\mathrm{o}$ seu caráter popular, por um lado, ao mesmo tempo que exasperava, por outro, líderes religiosos, que viam nessas celebrações apenas uma degradação dos costumes (Kiddy, 2005).

Nessa mesma época, todavia, alterações nessas estruturas sociais também começariam a se registrar. Entre 1870 e 1900, aproximadamente, a população de Minas Gerais cresceu a um ritmo sempre ligeiramente superior ao do Brasil. Em 1872, havia cerca de 2 milhões de habitantes em Minas Gerais. Em 1900 seriam cerca de 3,5 milhões, número que chegaria a quase 6 milhões em 1920. A construção de ferrovias a partir de meados da década de 1870 facilitou a integração da estrutura produtiva de Minas Gerais com outros centros consumidores do país - notadamente as cidades do Rio de Janeiro e de São Paulo. Como consequência, relações comerciais, financeiras e laborais em Minas Gerais foram se integrando cada vez mais a princípios de uma economia de mercado. Dessa forma, ao longo das primeiras décadas do século XX, Minas Gerais encontrava-se entre os três principais estados brasileiros em produto industrial, transportes e renda estadual (Wirth, 1982 p. 40).

No âmbito das artes, o circo foi uma das primeiras instâncias a materializar um novo modo de organização e oferta de oportunidades de consumo cultural em Minas Gerais. Registros documentais sobre a presença de circos na região existem desde meados do século XIX. No entanto, de início, a presença de circos ou outras companhias itinerantes de artes cênicas 
na região era irregular e ocasional. Segundo dados de Duarte (1993), entre 1858 e 1889, 28 circos realizaram apresentações em diferentes cidades de Minas Gerais (p. 335-342). A partir de 1890, porém, um visível crescimento no número desses espetáculos teve lugar. Ainda de acordo com os dados da mesma autora, apenas na década de 1890, mais de 60 circos realizaram apresentações em diferentes cidades de Minas Gerais.

A principal inovação que o aumento de circos na região materializava era uma inédita oferta comercial de oportunidades de consumo cultural. Os circos, afinal, eram empreendimentos comerciais liderados por empresários, cujos espetáculos, além de arte e cultura, também estavam submetidos a princípios econômicos da busca por lucro. Além disso, a partir da década de 1890, circos ofereceriam espetáculos em troca de pagamentos em dinheiro de modo frequente, ainda que bastante sazonal. Com o tempo, tais características iriam se intensificar e se ampliar, operando de modo cada vez mais frequente, além de afetar vários outros gêneros de diversão (Xavier; Amaral; Dias, 2019).

Por volta de 1920, uma pequena revolução dos costumes já estava em andamento em parte significativa de Minas Gerais. Nessa época, diversos novos espaços de lazer foram criados em várias cidades da região, tais como charutarias, restaurantes, bilhares, cafés, cervejarias, cinemas, bibliotecas, livrarias, rinques de patinação, hipódromos e campos de futebol. Esses estabelecimentos, além de serem em si mesmos novos em várias cidades, também ofereciam práticas cujos conteúdos eram do mesmo modo originais. Afora a sociabilidade típica de lugares onde se reúne, se come e se bebe, esses espaços também promoviam exibições de artes plásticas, projeções de filmes, apresentações musicais ou espetáculos cênicos variados. Durante as duas ou três primeiras décadas do século XX, joalherias, cafés, bilhares, confeitarias, bares, restaurantes e saguões de hotéis foram espaços importantes para o início da exibição de artes plásticas, quando então começaram a ser paulatinamente substituídos por locais mais especializados, como galerias e museus (Rossi, 1998-1999). Em Minas Gerais, muito sintomaticamente, a primeira exposição coletiva de arte moderna aconteceu em 1936, nas dependências de um bar que funcionava nas instalações de um cinema em Belo Horizonte (Almeida, 1997).

O jornalismo foi outra instância fundamental para a transformação da dinâmica cultural em Minas Gerais. Tipografias existiam na região desde o século XIX, apesar de suas dimensões serem quase sempre bastante 
modestas, marcadas por certo improviso e precariedade (Moreira, 2013). O primeiro jornal publicado em Minas Gerais foi O Compilador Mineiro, impresso em 1823 na cidade de Ouro Preto. Nas últimas décadas do século XIX, o número de jornais impressos em Minas Gerais aumentou muito expressivamente. Se entre 1828 e 1833 foram conhecidos 37 jornais, a partir de 1880 esse número ultrapassaria a marca da centena. Apenas na cidade de Juiz de Fora, a mais industrializada de Minas Gerais na época, 33 jornais foram lançados entre 1870 e 1889 (Moreira, 2013). A partir do século XX, mais ainda, tipografias não apenas cresceram em número, como também se espraiaram por diferentes regiões de Minas Gerais, o que acelerou e ampliou o alcance social da impressão de escritos, especialmente de jornais. Apenas na cidade de Belo Horizonte, capital de Minas Gerais desde 1898, mais de 430 jornais foram lançados até 1920, diante de uma população que oscilou, nesse período, entre 13 mil e 55 mil habitantes. Somente entre os anos de 1920 e 1925, mais de 69 títulos de jornais foram publicados em Belo Horizonte (Castro, 1995, p. 24). Nessa época, cerca de 266 periódicos eram publicados em mais de uma centena de diferentes cidades de Minas Gerais, que lançavam por volta de 1.300 edições todos os meses. Apenas o jornal Minas Geraes, que era publicado diariamente em Belo Horizonte, com uma tiragem média de 12 mil exemplares, imprimia cerca de 360 mil páginas por mês (Minas Gerais, 1926, v. IV, p. 297-307).

As marcas desse jornalismo, porém, eram a dispersão e a transitoriedade. Com poucas exceções, a maioria desses jornais nunca ultrapassou aquilo que se chamou um dia de "fatídica barreira do terceiro número" (Castro, 1995, p. 25). A maioria também não tinha motivações econômicas, embora quase sempre fossem comercializados. Em geral, naquele contexto, jornais eram criados a fim de dar visibilidade pública a interesses culturais, religiosos, associativos ou políticos bastante específicos. Tratava-se, em suma, de iniciativas artesanais e de pequeno alcance. Em tais circunstâncias, mesmo veículos de mais influência e longevidade, como o famoso jornal Diário de Minas, publicado entre 1898 e 1932, tinham poucos leitores. Não por acaso, contemporâneos falavam, com algum exagero, de uma "indiferença literária” da população de Minas Gerais (Werneck, 2012, p. 27).

Apesar dos exageros retóricos, de fato, era relativamente reduzido o número de leitores para iniciativas editoriais de Minas Gerais. Afora limitações estruturais, tais como maquinário gráfico ultrapassado, economia pouco monetizada e uma população pouco alfabetizada, havia ainda 
a concorrência de jornais editados no Rio de Janeiro, melhor produzidos, mais reputados e que eram distribuídos por várias cidades de Minas Gerais com certa facilidade, graças às numerosas estações ferroviárias que pontilhavam a região. Mesmo assim, a crescente publicação de jornais em várias cidades de Minas Gerais teve efeitos transformadores sobre a dinâmica cultural da região. Uma das consequências imprevistas desse processo foi o estímulo à produção literária. Vários nomes depois consagrados da literatura de Minas Gerais iniciaram suas carreiras de escritores trabalhando em jornais da região (Bomeny, 1994; Cury, 1998; Marques, 2011). Carlos Drummond de Andrade talvez seja a estrela maior dessa constelação de nomes, que incluem ainda Cyro dos Anjos, Pedro Nava, Fernando Sabino e muitos outros. Alguns livros dessa geração foram inicialmente publicados em jornais de Minas Gerais no formato de folhetins (tal como $O$ amanuense Belmiro ou Memórias de um Chauffer de Praça).

$\mathrm{Na}$ mesma época, iniciaram-se ainda a publicação de revistas literárias e revistas ilustradas que tal como os jornais, também exerceriam influências sobre a vida cultural da região. Quanto às revistas literárias, destaque-se a Revista Verde, publicada entre 1927 e 1929 na cidade de Cataguazes, no interior de Minas Gerais, por iniciativa de um grupo de jovens ligados a um grêmio literário da escola secundária local. A revista, cuja iniciativa foi precedida por três tentativas malsucedidas de se criar jornais, seria classificada depois por estudiosos do assunto como "uma das publicações mais interessantes do movimento modernista" (Werneck, 2012, p. 66). De fato, os jovens de Cataguazes que editaram a revista trocaram correspondências e foram publicamente elogiados por personagens da vanguarda do modernismo brasileiro, embora tenham sido quase inteiramente ignorados na própria cidade. Já às revistas ilustradas, de modo totalmente diferente, não despertaram tanto entusiasmo de artistas e intelectuais de vanguarda, mas atraíram relativo interesse do público. Com um caráter mais marcadamente comercial, apelando ostensivamente para a publicidade, as revistas ilustradas buscavam agradar potenciais leitores por meio da combinação de informação e entretenimento, em fórmula que já era conhecida no Brasil desde o final do século XIX (cf. Luca, 2018; Martins, 2008; Mauad, 2005). Em Minas Gerais, essas revistas foram publicadas exclusivamente em Belo Horizonte, cujos títulos Semana Illustrada e Revista Alterosa são as que alcançaram maior repercussão (Barros, 2018; Mota, 2018; Pereira, 2011). 
Outra atividade cultural de relativo sucesso popular no começo do século XX foi o teatro. $\mathrm{O}$ uso das linguagens orais e corporais, que dispensavam a capacidade de leitura do público, era provavelmente um dos motivos para o sucesso do teatro no período, dado que ampliava significativamente o número de pessoas que poderiam acessar tais espetáculos. Além disso, até onde é possível saber, o repertório das peças teatrais encenadas em Minas Gerais nesse período, tal como acontecia em outras regiões do Brasil, parecia estar em conformidade com predileções do gosto popular, valorizando a comédia e os propósitos de diversão do público, em detrimento do drama, que geralmente tinha ambições educativas e até civilizatórias. Em Diamantina, por exemplo, cidade no norte de Minas Gerais, ao longo de toda a primeira década do século XX predominaram espetáculos cômicos de variedades, com marcante uso de magia, ilusionismo, ginástica e malabarismos (Oliveira, 2016). Registros sobre o teatro na cidade de São João del-Rei em meados da década de 1910 também dão notícias sobre o predomínio de repertórios cômicos (Sá, 2019; Guilarduci, 2019). Em Belo Horizonte, do mesmo modo, a crítica teatral especializada, que já existia na cidade por volta da década de 1920, também deu notícias do predomínio nos palcos da capital de "operetas" e "peças esfuziantes de humor", também chamadas criticamente de "gêneros menores", compatíveis com o "gosto das grandes massas" e explicitamente preocupadas em fazer rir, conforme diziam esses críticos, "uma verdadeira fábrica de gargalhadas" (Cury, 1998, passim).

A partir de 1910, aproximadamente, exibições de filmes foram outro gênero de espetáculos que ganharam destaque em várias cidades de Minas Gerais. Geralmente introduzido na região por exibidores ambulantes ainda nos primeiros anos do século XX, em pouco tempo cinemas estariam instalados junto a outros estabelecimentos comerciais ou eventualmente em edifícios especialmente destinados a esse fim, mas já não mais de forma itinerante (Arruda, 2009; Lino, 2009). A especialização desses estabelecimentos, todavia, era ainda relativa, uma vez que além de filmes, tais locais também ofereciam lutas de boxe, apresentações musicais, teatrais, circenses e outros espetáculos de variedades, não por caso ostentando frequentemente o nome de "cineteatros". Em 1920, de acordo com os dados do Anuário Estatístico, havia 252 cinemas em Minas Gerais (Minas Gerais, 1926, p. 342). Nessa época, afora os cinemas e cineteatros, Minas Gerais era um dos estados do Brasil com maior oferta relativa de "casas de espetáculos" (Dias, 2018, p. 390). 
No que diz respeito especificamente aos filmes que eram exibidos nesses estabelecimentos, em conformidade ao que se passava no mercado exibidor brasileiro do período, predominavam filmes europeus até 1914, e norte-americanos depois disso (cf. Simis, 2015). Além de um mercado exibidor relativamente grande, Minas Gerais contou também com pequenas redes de produção de filmes, notadamente nas cidades de Belo Horizonte, Juiz de Fora e Cataguazes, onde se destacam os nomes de Igino Bonfioli, João Carriço e Humberto Mauro, respectivamente (Almeida, 1999; Andries, 2001; Gomes, 1974; Gomes, 2008; Lobato, 1987; Morettin, 2013).

A partir das décadas de 1930 e 1940, aproximadamente, na esteira de transformações na estrutura produtiva da economia brasileira como um todo, uma aceleração da industrialização teria lugar em Minas Gerais nesse período. Depois de um "surto agrícola" voltado para o mercado exportador e para o abastecimento alimentar nas décadas de 1910 e 1920, a indústria siderúrgica e, pouco depois, indústrias de bens de consumo de massa (sobretudo têxteis e alimentos) são os principais fatores responsáveis pelo crescimento econômico de Minas Gerais a partir de 1930 (Singer, 1974). No âmbito da cultura, o surgimento de um mercado de consumo propriamente de massas, isto é, capaz de viabilizar a produção, a distribuição e a comercialização de artes e espetáculos em grande escala, é uma das principais novidades a partir da década de 1930. Nessa época, veículos de imprensa de Minas Gerais com alcance até então estritamente regionais são integrados a grandes conglomerados de comunicação com alcance nacional. A aquisição do jornal Estado de Minas, e depois da Revista Alterosa pelo grupo do famoso empresário da comunicação Assis Chateaubriand, está entre os principais exemplos nesse sentido (Morais, 1994; Barros, 2018). Ainda no mercado editorial, em 1950 a primeira grande editora de livros de Minas Gerais seria inaugurada: a editora Itatiaia (Hallewell, 1985; Santos et al., 2011).

Além de forças de mercado, estruturas de governo também atuariam muito mais decisivamente na produção cultural brasileira a partir da década de 1930 (Williams, 2001; Velloso, 2012). Em Minas Gerais, em 1936, por iniciativa do governo estadual, foi inaugurada uma grande rádio emissora na região: a Rádio Inconfidência (Cota, 2016). No âmbito das artes eruditas, também por iniciativa do governo de Minas Gerais, foi criada em meados da década de 1940 uma escola de formação em belas-artes, que 
exerceria importante influência sobre a formação e também sobre a produção artística em artes plásticas da região nos anos seguintes (Moura, 1993).

Pouco a pouco, Belo Horizonte, a capital de Minas Gerais, consolida-se não apenas como centro político e administrativo do Estado, mas também como importante centro econômico (Singer, 1974). A partir de meados da década de 1970, como causa e consequência de um processo de crescimento econômico acelerado no Brasil, uma mentalidade administrativa e gerencial mais firmemente orientada para a busca de lucros sedimenta-se também nas cadeias produtivas da cultura (Ortiz, 1994). A pequena ampliação das classes médias ou a concentração de renda nesse segmento de classe, bem como a elevação dos índices de alfabetização favoreceram o consumo de bens de consumo de luxo, incluindo uma série de serviços ligados ao lazer e a cultura (Dias; Melo, 2011; Ridenti, 2014). Em Minas Gerais, em particular, por iniciativa privada e empresarial, surgem os primeiros grupos profissionais de dança e teatro comercialmente viáveis e artisticamente bem-sucedidos: o Grupo Corpo, na dança; além do Grupo Giramundo e do Grupo Galpão, no teatro (Dias; Borges Junior, 2016; Moreira, 2010; Alves; Noe, 2006).

\section{Aspectos metodológicos: a compatibilização terri- torial e a técnica de cluster}

Neste trabalho, analisamos o modo de distribuição territorial de equipamentos culturais em Minas Gerais entre os anos de 1920 e 2010. Para isso, aplicamos o método de aglomeração a informações sociodemográficas e culturais obtidas de três diferentes fontes: a) o Anuário Estatístico de Minas Gerais de 1920; b) o Perfil de Municípios Brasileiros (MUNIC) de 2006; c) o Censo Demográfico de 2010.

Mais especificamente, extraímos desses documentos e submetemos ao método de aglomeração informações referentes ao percentual da população alfabetizada, ao percentual de domicílios ligados à estrutura de esgotamento sanitário e ao número de cinemas e teatros de todos os municípios de Minas Gerais nesses dois períodos. Dados sobre o número de cinemas e teatros oferecem um indicativo da disponibilidade de oferta cultural comercial em uma cidade. Dados sobre o percentual de domicílios conectados a redes de esgotamento sanitário, por outro lado, indicam o seu grau de 
desenvolvimento urbano, que por sua vez podem ter efeitos sobre a capacidade de o lugar atrair e fixar indivíduos propensos ao consumo cultural, o que obviamente interfere na dinâmica de oferta e consumo desses bens e serviços. Finalmente, o tamanho percentual da população alfabetizada também pode ser outra indicação genérica do alcance potencial do mercado consumidor para artes e culturas, uma vez que predisposições subjetivas obtidas por meio de escolarização prolongada são fatores recorrentemente apontados como determinantes para o consumo de certos bens e serviços culturais. A escolaridade também guarda efeitos positivos sobre a renda, ampliando, assim, seu alcance potencial sobre as disposições para o consumo de bens e serviços culturais, dado que recursos financeiros adicionais podem vir a ser convertidos nesse tipo de consumo de luxo (Veal, 2006). Nesse sentido, o uso de informações sobre a escolaridade teria sido mais apropriado aqui, em vez de apenas a alfabetização. Todavia, tais informações não estão disponíveis para o período de 1920, pelo que foram então adotados a alfabetização como um indicador aproximado.

O uso do número de cinemas e teatros, em particular, sem considerações sobre outros equipamentos culturais, como museus ou bibliotecas, por exemplo, parece-nos oportuno aos propósitos deste estudo, na medida em que os cinemas e os teatros constituíram, muitas vezes de formas articuladas, duas das modalidades de consumo cultural mais precocemente submetidas a mecanismos de uma economia de mercado.

O primeiro tratamento metodológico para alcance dos objetivos desse artigo é a compatibilização dos municípios. Em 1920, o estado de Minas Gerais contava com 178 municípios e, em 2010, com 853. Nos 90 anos de intervalo entre os dois registros, foram criados vários municípios por emancipação e outros poucos foram agregados. Assim, para assegurar a comparação, foi feito um primeiro exercício de reordenação da divisão de 2010 tendo-se por referência 1920. Por meio do programa IBGE Cidades, foi feita a comparação das divisões territoriais nos dois anos de análise. Após organização dessas informações, calculou-se a média (no caso dos dados referentes à taxa de alfabetização e acesso ao sistema de esgoto) ou soma (no caso dos dados referentes ao número de teatros e número de cinemas) das variáveis dos municípios desmembrados em relação àqueles definidos em 1920.

Assim, seguidas emancipações e reorganizações administrativas no ordenamento territorial de municípios como o de Barbacena, para ter- 
mos um exemplo concreto, fez com que o território da cidade em 1920 equivalesse a outros 11 municípios em 2010: além de Barbacena, Antônio Carlos, Senhora dos Remédios, Oliveira Fortes, Paiva, Desterro do Melo, Ibertioga, Santa Bárbara do Tugúrio, Alfredo Vasconcelos, Caranaíba e Santa Rita de Ibitipoca (sendo que esses três últimos sofreram ainda mudanças de nome ao longo do período). Desde 1920, processos semelhantes aconteceram com outros 154 municípios. Apenas 24 municípios, portanto, não sofreram processos desse tipo ao longo desse período. Para efeitos dos nossos cálculos, no entanto, os municípios que haviam surgido entre 1920 e 2010 tiveram os percentuais de população alfabetizada e de domicílios ligados à rede de esgoto somados, bem como os números dos seus cinemas e dos seus teatros. Esses resultados foram então comparados aos números relativos a 1920 dos municípios dos quais eles foram desdobrados originalmente.

\section{Figura 1 Divisão do estado de Minas Gerais em municípios em 1920}

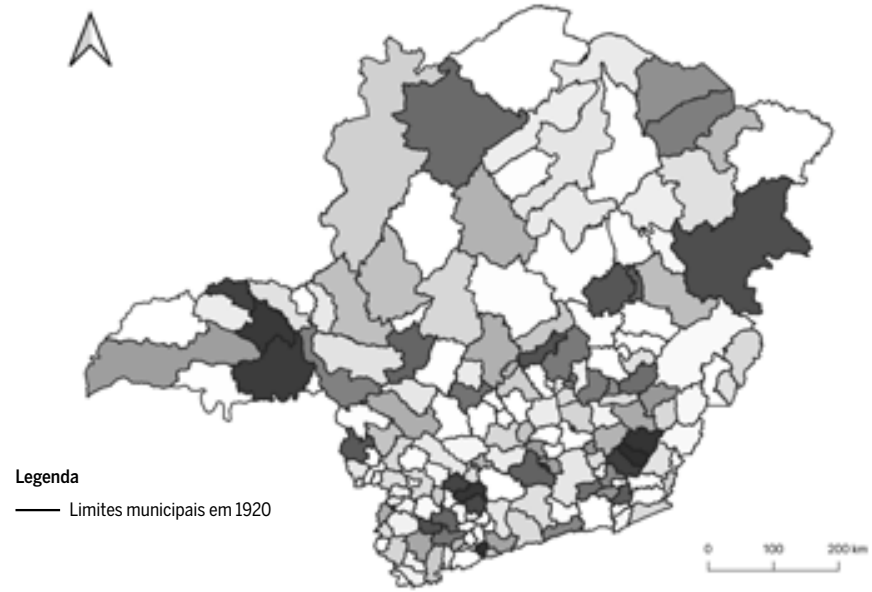

Fonte: Minas Gerais, 1926. Elaboração própria.

As figuras 1 e 2 trazem a divisão do estado em municípios em 1920 e 2010, respectivamente. Na Figura 2, o traçado mais fraco evidencia a territorialização de 2010, com seus 853 municípios. A divisão por cores busca mostrar onde eles estariam se fosse mantida a mesma divisão de 1920. 


\section{0}

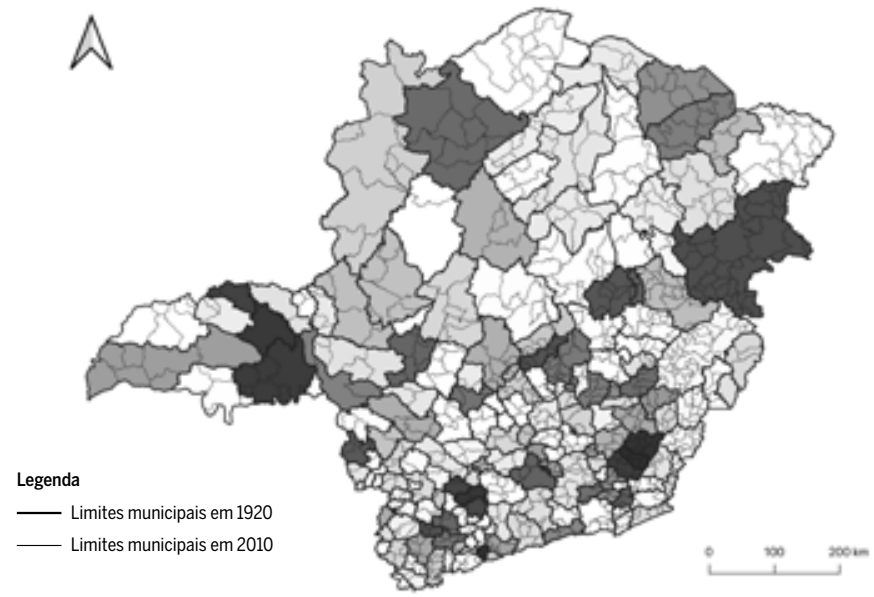

Fonte: Brasil, 2010. Elaboração própria.

Ao conjunto de variáveis, é aplicado o método de aglomeração (clustering). Essa técnica estatística classifica suas partes em conjuntos homogêneos a partir de variáveis de $n$-dimensões pré-escolhidas, possibilitando a formação de uma tipologia, no caso territorial. Com respeito a cada variável, define se o indivíduo (município $=x$ ) pertence a uma dada categoria. Se a decisão é de aceitar ("=1") ou rejeitar ("=0") tal proposição. A função de pertinência de um conjunto A com relação a x pode ser descrita como:

$$
A(X)=\left\{\begin{array}{l}
1, \operatorname{sex} \in A \\
0, \operatorname{sex} \notin A
\end{array}\right\}
$$

Várias podem ser as métricas usadas no procedimento de geração de clusters. Para tanto, especificidades dos dados, características estatísticas das variáveis e os objetivos da classificação devem ser contempladas. Entre as várias técnicas, optamos, neste estudo, pelo K-means, que estabelece a distância entre a observação e a média. Se a observação estiver próxima da média, pertence ao conjunto. Caso contrário, não (Mingoti, 2007).

Para os 178 municípios, consideram-se percentual da população alfabetizada, proporção de domicílios com acesso a esgoto, número de teatros e nú- 
mero de salas de cinemas. A configuração de 2010 reescrita em 1920 ocorreu por meio da soma das informações dos municípios desmembrados quando a variável estava expressa em número absoluto ou em médias ponderadas pela população (caso estivesse em percentual). Considerando, portanto, essa estratégia metodológica, trazemos na próxima seção os resultados dos aglomerados de Minas Gerais em 1920 e em 2010 na distribuição territorial de 1920, buscando evidenciar sua natureza e a evolução no tempo.

\section{Resultados e discussões}

Segundo registros do Anuário Estatístico, um calhamaço de mais de 3.300 páginas, distribuídas por cinco volumes, em 1920, Minas Gerais contava uma população de quase 5,9 milhões de habitantes (o número preciso é 5.888.174), que tinham à disposição 252 cinemas e 296 teatros. Em certa medida, esses números podem ser vistos como superestimados, uma vez que cinemas que também oferecessem espetáculos teatrais, musicais ou de variedades, além das exibições de filmes propriamente ditos, foram registrados duas vezes no documento, isto é, aparecem na listagem dos cinemas e também na dos teatros. Em 1920, quase todos os cinemas enquadravam-se nessa situação, na medida em que era usual que a exibição de filmes fosse alternada ou intercalada com espetáculos cênicos diversos (Araújo, 1981). Não por acaso, muitos cinemas ostentavam, por isso mesmo, o nome de "cineteatro", mais literalmente compatível com a natureza dos serviços ofertados naqueles estabelecimentos. Em todo caso, considerando o conjunto de 178 municípios da época e os números registrados neste Anuário Estatístico, que foram os que tomamos para efeitos de cálculos deste estudo, em média, haveria 1,4 cinemas e 1,6 teatros disponíveis para cada um dos municípios de Minas Gerais na época. Nesses termos, $26 \%$ dos municípios (48) gozavam de uma oferta de teatros e cinemas acima dessa média. Em termos populacionais, haveria, em média, um cinema para 23.365 habitantes e um teatro para 19.892 habitantes.

Do mesmo modo, para o ano de 2006, o Perfil de Municípios Brasileiros também oferece informações relativamente abundantes a respeito de equipamentos culturais. Dados demográficos para o período estão disponíveis no Censo de 2010. Nessa época, de acordo com o Censo, Minas Gerais contava com uma população de quase 19,6 milhões de habitantes 
(19.597.330), distribuída por 853 municípios. Segundo dados disponibilizados pela pesquisa sobre o Perfil de Munícipios Brasileiros, esses municípios tinham à sua disposição 320 teatros e 176 cinemas. Considerando o conjunto dos municípios, em média, haveria 0,2 cinemas e 0,3 teatros em cada um desses municípios. Assim, nota-se que apenas 8,5\% dos municípios de Minas Gerais (73) em 2006-2010 gozavam de uma oferta de teatros e cinemas acima dessa média. Em termos populacionais, haveria, em média, um cinema para 111.348 habitantes e um teatro para 61.242 habitantes.

Como já informado, para cada um dos anos, aplicou-se a técnica de clustering $\mathrm{k}$-means às variáveis selecionadas. Foram obtidos quatro aglomerados, ${ }^{1}$ distribuídos, conforme descrito na Tabela 1.

Tabela 1 Distribuição dos municípios mineiros segundo clusters

\begin{tabular}{l|rr|r|r}
\hline \multirow{2}{*}{ Anos } & $\mathbf{n}$ & $\mathbf{1 9 2 0}$ & $\mathbf{N}$ & $\mathbf{2 0 0 6 - 2 0 1 0}$ \\
\cline { 2 - 5 } & 7 & $\mathbf{\%}$ & 1 & $\mathbf{\%}$ \\
\hline Cluster 1 & 8 & $4 \%$ & 104 & $58 \%$ \\
\hline Cluster 2 & 41 & $23 \%$ & 62 & $35 \%$ \\
\hline Cluster 3 & 122 & $69 \%$ & 11 & $6 \%$ \\
\hline Cluster 4 & 178 & $100 \%$ & 178 & $100 \%$ \\
\hline Total & & & &
\end{tabular}

Fonte: Brasil, 2010; Minas Gerais, 1926. Elaboração própria.

O cluster 1, nos dois períodos, reúne o menor número de municípios: 7 em 1920 (4\% do total) e apenas 1 em 2010 (1\% do total). Nos dois períodos, estes clusters representam uma situação privilegiada. Em 1920, encontravam-se nesta posição os municípios de Além Paraíba, Belo Horizonte, Juiz de Fora, Santa Luzia, São Sebastião do Paraíso, Ubá e Viçosa, que contavam, em média, 5,1 cinemas e 5,7 teatros. Em 2010, apenas Belo Horizonte achava-se aí, contando 33 teatros e 8 cinemas. Todos os demais municípios que não Belo Horizonte experimentaram uma piora relativa nos indicadores analisados neste estudo: deixaram de integrar o cluster com os maiores indicadores das variáveis consideradas, situando-se em um grupo de municípios que contava, em 2006-2010, um número médio de cinemas e teatros inferior ao de 1920.

1 Quatro grupos foram escolhidos na tipologia, uma vez que se mostrou como a melhor divisão, dada a presença de muitas variáveis com incidência de zero, especialmente em 1920, e a presença de poucas variáveis na estimação (quatro). 
O cluster 2 reúne, em 1920 e 2006-2010, os municípios com os segundos maiores indicadores das variáveis selecionadas, em uma situação geral que poderia ser descrita como "intermediária", isto é, que nem gozavam de acesso abundante ou privilegiado a oportunidades de consumo cultural, tampouco se encontravam em situação de escassez dessas oportunidades. Em 1920, eram 8 municípios nessa posição (4\% do total): Formiga, Itajubá, Nepomuceno, Oliveira, Ouro Preto, Palma, Paraguaçu e Uberaba. Em média, esses municípios contavam 3 cinemas e 3,4 teatros. Em 2006-2010, eram 104 municípios neste cluster (58\% do total), representando, então, o agrupamento que caracterizava a situação da maior parte dos municípios de Minas Gerais com relação ao acesso a oportunidades de consumo de cultura no período. São municípios que contavam, nessa época, em média, 1,2 cinemas e 1,7 teatros.

Já o cluster 3 engloba os municípios com os terceiros maiores indicadores das variáveis selecionadas, em uma situação geral que ainda poderia ser descrita como "intermediária", mas já ligeiramente próxima a uma situação de pequena escassez de oportunidades de acesso ao consumo cultural, especialmente para o período 2006-2010, quando os números médios de teatros e sobretudo de cinemas diminuem significativamente. Em 1920, eram 41 municípios nessa posição ( $23 \%$ do total), que contavam, em média, 2,6 cinemas e 2,7 teatros. Em 2006-2010, eram 62 municípios (35\% do total), que contavam, em média, 0,7 cinemas e 1,6 teatros.

Tabela 2 Distribuição e média das variáveis selecionadas por clusters em 1920 e 2006-2010*

\begin{tabular}{|c|c|c|c|c|c|c|c|c|c|c|}
\hline \multirow[t]{2}{*}{ Anos } & \multicolumn{5}{|r|}{1920} & \multicolumn{5}{|r|}{ 2006-2010 } \\
\hline & 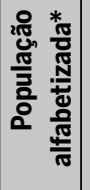 & 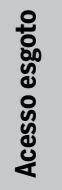 & 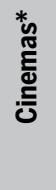 & 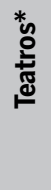 & 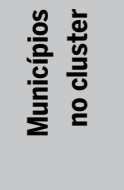 & 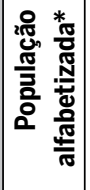 & 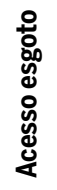 & 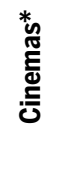 & 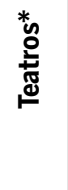 & 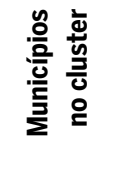 \\
\hline Cluster 1 & $31 \%$ & $26 \%$ & 5,1 & 5,7 & $7(4 \%)$ & $97 \%$ & $87 \%$ & 8 & 33 & $1(1 \%)$ \\
\hline Cluster 2 & $24 \%$ & $8 \%$ & 3 & 3,4 & $8(4 \%)$ & $91 \%$ & $75 \%$ & 1,2 & 1,7 & $104(58 \%)$ \\
\hline Cluster 3 & $25 \%$ & $4 \%$ & 2,6 & 2,7 & $41(23 \%)$ & $87 \%$ & $48 \%$ & 0,7 & 1,6 & $62(35 \%)$ \\
\hline Cluster 4 & $20 \%$ & $2 \%$ & 0,5 & 1 & $122(69 \%)$ & $83 \%$ & $10 \%$ & 0,2 & 0,8 & $11(6 \%)$ \\
\hline Total & & & & & $178(100 \%)$ & & & & & $178(100 \%)$ \\
\hline
\end{tabular}

Fonte: Brasil, 2010; Minas Gerais, 1926. Elaboração própria.

* Informações sobre os desvios-padrão se encontram no Anexo (Tabela A1). 
Por último, o cluster 4 traz os municípios com os menores indicadores das variáveis selecionadas. Esses aglomerados reúnem os municípios cuja situação geral de oportunidades de acesso ao consumo cultural, sempre medida pelo número de cinemas e teatros disponíveis, pode ser descrita como escassa. Tanto em 1920 quanto em 2010, esses também são os municípios com piores indicadores relativos ao percentual da população alfabetizada e de domicílios ligados a rede de esgoto (conforme Tabela 2).

Conforme indicam nossas análises, houve uma aguda diminuição de clusters que reuniam cidades com menores indicadores das variáveis selecionadas. Em 1920, a maioria dos municípios (69\%) reunia-se no cluster 4. Em 2006-2010, esse cluster, que reunia os municípios com os menores indicadores nas variáveis selecionadas, tinha se reduzido significativamente, contando, agora, apenas 11 municípios (em vez de 122, como era em 1920), o que representava apenas $6 \%$ do total (em vez de $69 \%$, como era em 1920). Em 2006-2010, a maioria dos municípios, (58\%) encontravam-se no cluster 2 , que reunia os segundos maiores indicadores das variáveis selecionadas, o que indicaria uma melhora geral relativa, embora o número médio de cinemas e teatros neste cluster representasse, nessa época, cerca de metade do número médio de teatros e cinemas disponíveis para esse mesmo cluster em 1920.

Figura 3 Distribuição territorial dos clusters em 1920

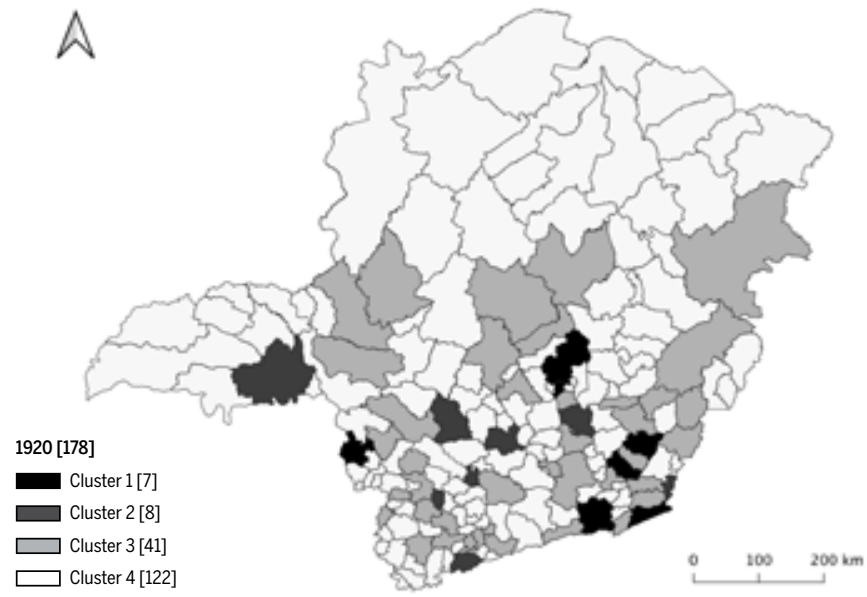

Fonte: Minas Gerais, 1926. Elaboração própria. 
Figura 4 Distribuição territorial dos clusters em 2006-2010

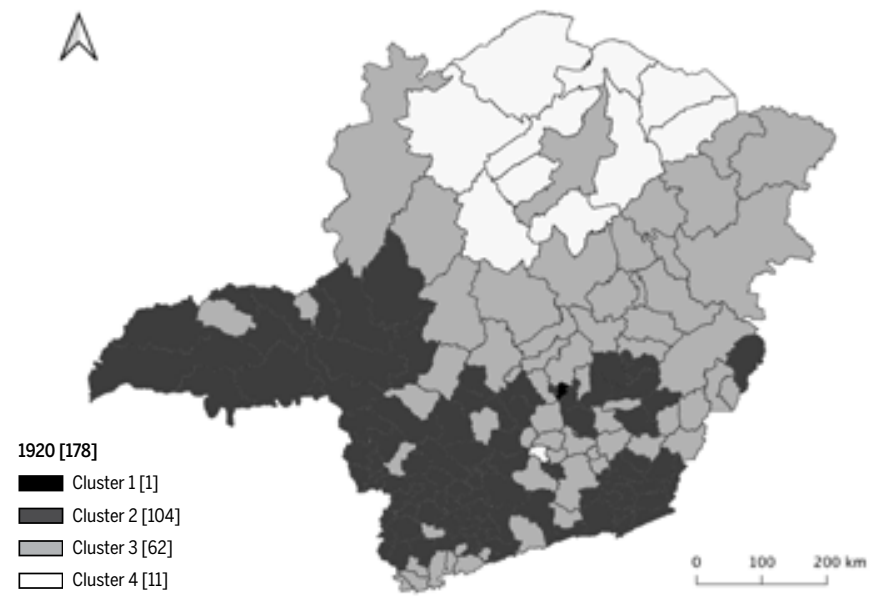

Fonte: Brasil, 2006. Elaboração própria.

Uma vez que os números de teatros e cinemas diminuíram entre 1920 e 2010, ao mesmo tempo que os percentuais da população alfabetizada e dos domicílios com acesso a redes de esgoto aumentaram, mudanças nas posições dos municípios em direção aos clusters que reúnem os maiores indicadores entre as variáveis utilizadas aqui devem ser em grande medida tributadas a melhoras no letramento e no saneamento básico, e não a quaisquer evoluções ou aprimoramentos das dinâmicas no mercado de oferta e de consumo cultural. No que diz respeito aos cinemas e aos teatros, mais especificamente, as oportunidades gerais de acesso ao consumo desses bens culturais, com efeito, diminuíram no período que analisamos aqui. A diminuição geral dessas oportunidades parece ser explicada em grande medida pela intensa concentração de cinemas e teatros que teve lugar entre 1920 e 2010. Essa intensa concentração de cinemas e teatros em apenas alguns poucos municípios dramatiza uma das transformações históricas mais notáveis na dinâmica cultural e socioeconômica de Minas Gerais nesse período. Em 2006-2010, apenas 11 municípios (que equivalem a pouco mais de $1 \%$ do total de 853 municípios) concentravam $50 \%$ de todos os cinemas de Minas Gerais. No limite, são esses municípios com elevadas concentrações de cinemas e teatros que respondem por boa parte dos números médios de equipamentos culturais dos clusters do período de 2006-2010. 
O caso de Belo Horizonte ilustra exemplarmente não apenas esse processo de concentração na oferta e no consumo cultural em Minas Gerais, mas também, de forma mais profunda, o modo como o desenvolvimento econômico mais geral pode afetar esse segmento de atividades. Entre 1920 e 2010, a posição relativa de Belo Horizonte diante dos demais municípios de Minas Gerais melhorou significativamente. Em 1920, Belo Horizonte integrava o cluster com maiores indicadores das variáveis utilizadas neste estudo, ao lado de outros seis municípios. Já em 2006-2010, Belo Horizonte integrava esse mesmo cluster sozinho. Os outros seis municípios que antes lhe acompanhavam foram superados, considerando-se os indicadores utilizados pelas variáveis que selecionamos para este estudo.

O aprofundamento relativo dessa concentração em Belo Horizonte provavelmente relaciona-se com a própria dinâmica econômica e territorial mais geral que afetou Minas Gerais ao longo do século XX, evidenciando que a urbanização e as economias de aglomeração de fato tendem a favorecer regiões metropolitanas na constituição de clusters culturais.

Obviamente, atividades culturais seguem encontrando lugar em outros municípios de Minas Gerais, em que pese a nova concentração dessas atividades em Belo Horizonte. Cidades como Barbacena, Lavras, Varginha, Montes Claros, Poços de Caldas, Uberaba, Uberlândia e Juiz de Fora, entre algumas outras, contam atualmente com significativas concentrações de alguns equipamentos culturais, notadamente cinemas e teatros. No entanto, boa parte dos municípios que antes gozavam de certas oportunidades de consumo cultural, mesmo que de modo modesto, agora se encontra quase inteiramente desprovida dessas oportunidades (embora outras oportunidades para o consumo de outras linguagens artísticas e culturais seguramente existam).

\section{Considerações finais}

De modo geral, nos dois períodos, os clusters que reúnem os maiores indicadores de oportunidades de acesso ao consumo cultural reúnem também os maiores percentuais da população alfabetizada e os maiores índices de domicílios com acesso a rede de esgoto, conforme se vê na Tabela 2. Em sentido contrário, também nos dois períodos, os clusters que reúnem os menores indicadores de oportunidades de acesso ao consumo cultural reúnem também os menores percentuais da população alfabetizada, além dos 
menores índices de domicílios com acesso a rede de esgoto. No entanto, não deriva daí nenhuma relação de causalidade. Por um lado, é possível que cidades com melhores condições de infraestrutura urbana tenham de fato se tornado mais atraentes para indivíduos dotados de elevado capital cultural, tais como artistas, por exemplo, que tendem a ter maior propensão de se engajarem na oferta e no consumo de bens e serviços culturais. Ao fixarem residência nessas cidades, esses indivíduos elevariam também o estoque de capital humano disponível ali, como indicariam os percentuais da população alfabetizada mais elevados, com efeitos possíveis sobre as dinâmicas mais gerais de desenvolvimento econômico. Assim, estabelecer-se-ia uma cadeia de relações entre amenidades urbanas, cultura e desenvolvimento econômico.

Por outro lado, porém, tanto a infraestrutura urbana melhorada, com seus índices maiores de acesso a esgotamento sanitário e oportunidades de acesso ao consumo cultural, quanto a própria aglomeração de uma população mais alfabetizada poderiam também ser os resultados, e não as causas, de outras dinâmicas socioeconômicas mais gerais. Uma aceleração do crescimento econômico também pode ter o poder de atrair e fixar novos residentes, interessados, então, em tentar explorar oportunidades que surjam desse processo. Com o crescimento demográfico, a dinâmica econômica já em ascensão poderia ser reforçada, na medida em que o tamanho do mercado consumidor também estaria em progressiva ampliação, aumentando a demanda por bens e serviços diversos, que ao menos em parte poderiam ser fornecidos por produtores locais. Tudo isso poderia ainda ter efeitos fiscais, ampliando a capacidade do poder público local de investir em melhoramentos urbanos, tornando a cidade submetida a essa dinâmica ainda mais atraente para indivíduos dotados de elevado capital cultural, cujas presenças elevaria o estoque de capital humano, com seus presumíveis efeitos sobre a produtividade e o desenvolvimento econômico. Em conjunto, essa cadeia de relações criaria um círculo virtuoso e favorável ao crescimento econômico.

\section{Referências}

ALMEIDA, C. A. O cinema como "agitador de almas": Argila, uma cena do Estado Novo. São Paulo: Annablume/FAPESP, 1999. 
ALMEIDA, M. das G. de. Belo Horizonte e metrópole: memória das artes plásticas na capital mineira. In: RIBEIRO, M. A.; SILVA, F. P. (Org.). Um século de história das artes plásticas em Belo Horizonte. Belo Horizonte: C/Arte, 1997, p. 70-112.

ALVES, J.; NOE, M. O palco e a rua: a trajetória do teatro do Grupo Galpão. Belo Horizonte: Editora PUC Minas, 2006.

AMARAL, D. V. de O.; DIAS, C. Lazer e mercado do entretenimento em uma cidade rural de Minas Gerais. Lócus, v. 25, n. 1, p. 62-85, 2019.

ANDRIES, A. O cinema de Humberto Mauro. Rio de Janeiro: FUNARTE, 2001. 018.pdf. Acesso em: 11 nov. 2019.

ARAÚJO, V. de P. Salões, circos e cinemas de São Paulo. São Paulo: Editora Perspectiva, 1981.

ARRUDA, R. P. de. Olindo Belém, fotógrafo de Belo Horizonte. Revista do Arquivo Público Mineiro, v. 45, n. 1, p. 48-67, 2009.

BARROS, G. A. de. Para a família do Brasil: o cultivo do corpo e a diversão em Belo Horizonte nas páginas da revista Alterosa (1939-1945). Tese (Doutorado em Estudos do Lazer) - Universidade Federal de Minas Gerais Belo Horizonte, 2018.

BLAUG, M. Where are we now on cultural economics. Journal of Economic Surveys, v. 15, n. 2, p. 123-143, 2001.

BOMENY, H. Guardiões da razão: modernistas mineiros. Rio de Janeiro: Tempo Brasileiro, 1994.

BRASIL. Pesquisa de Informações Básicas Municipais - perfil dos municípios brasileiros: 2006. Rio de Janeiro: Instituto Brasileiro de Geografia e Estatística (IBGE), 2006. Disponível em: $<$ https://www.ibge.gov.br/estatisticas/sociais/saude/19879-suplementos-munic2.html? edicao $=10637 \& \mathrm{t}=$ destaques $>$. Acesso em: 21 nov. 2019.

BRASIL. Censo Demográfico 2010. Rio de Janeiro: Instituto Brasileiro de Geografia e Estatística (IBGE), 2010. Disponível em: <https://censo2010.ibge.gov.br/>. Acesso em: 24 out. 2019

CABREJO, F. M. The New Order: diversions and Modernization in Turn-of-the-Century Lima. In: BEEZLEY, W. H.; CURCIO, L. A. (Ed.). Latin American Popular Culture since Independence: An Introduction. New York: Rowman \& Littlefield. 2012, p. 153-163.

CASTRO, M. C. P. S. Efêmeros e permanentes: os ardis da memória da imprensa de Belo Horizonte. In: LINHARES, Joaquim Nabuco. Itinerário da imprensa de Belo Horizonte: 1895 1954. Belo Horizonte: Fundação João Pinheiro / Centro de Estudos Históricos e Culturais, 1995.

CHAPAIN, C; PROPIS, L. Drivers and Processes of Creative Industries in Cities and Regions, Creative Industries Journal, 2:1, 9-18, 2009

COTA, L. M. da Conceição. Rádio, educação e formação da identidade nacional: um estudo da Rádio Inconfidência de Minas Gerais (1930-1950). Dissertação (Mestrado em Educação, Conhecimento e Inclusão Social) - Universidade Federal de Minas Gerais, Belo Horizonte, 2016.

CURY, M. Z. F. Horizontes modernistas: o jovem Drummond e seu grupo em papel jornal. Belo Horizonte: Autêntica, 1998.

DIAS, C. Mercantilização do lazer no Brasil. Licere, v. 21, n. 2, p. 364-403, jun. 2018. 
DIAS, C.; BORGES JUNIOR, M. de A. História da formação do Grupo Corpo: dança moderna e indústria cultural no Brasil dos anos 1970. Repertório: teatro e dança, ano 19, n. 26, p. 252-265, 2016.

DIAS, C.; MELO, V. A. de. Leisure and urbanization in Brazil from the 1950s to the 1970s. Leisure Studies, v. 30, issue 3, p. 333-343, 2011.

DUARTE, R. H. Noites circenses: espetáculos de circo e teatro em Minas Gerais no século XIX. Tese (Doutorado em História) - Universidade Estadual de Campinas, Campinas, 1993.

GOMES, P. A. Pioneiros do cinema em Minas Gerais. Belo Horizonte: Crisálida, 2008.

GOMES, P. E. S. Humberto Mauro, Cataguases, Cinearte. São Paulo: Perspectiva, 1974.

GUILARDUCI, C. O teatro de revista em São João del-Rei: espaços de lazer. In: DIAS, C.; ROSA, M. C. Histórias do lazer nas Gerais. Belo Horizonte: Editora UFMG, 2019, p. 85-112.

HALLEWELL, L. O livro no Brasil: sua história. São Paulo: Ed. da USP, 1985.

JACOBS, J. Morte e vida das grandes cidades. 3. ed. São Paulo: WMF Martins Fontes, 2011.

KIDDY, E. W. Blacks of the Rosary: Memory and History in Minas Gerais, Brazil. Pennsylvania: The Pennsylvania State University Press, 2005.

LAZZERETTI, L. Introduction. In: LAZZERETTI, L. Creative Industries and Innovation in Europe: Concepts, Measures and Comparative Case Studies. Londres, 2013. Série Regions and Cities.

LAZZERETTI, L.; BOIX, R.; CAPONE, F. Why Do Creative Industries Cluster? In: LAZZERETTI, L. Creative Industries and Innovation in Europe: Concepts, Measures and Comparative Case Studies. Londres, 2013. Série Regions and Cities.

LINO, S. C. Cinematographo: doença da moda. Revista do Arquivo Público Mineiro, v. 45, n. 1, p. 90-103, 2009.

LOBATO, A. L. Os ciclos regionais de Minas Gerais, Norte e Nordeste (1912-1930). In: RAMOS, F. (Org.). História do cinema brasileiro. São Paulo: Art Editora, 1987.

LUCA, T. R. de. A ilustração (1884-1892): circulação de textos e imagens entre Paris, Lisboa e Rio de Janeiro. São Paulo: Editora da Unesp, 2018.

MACHADO, A. F.; SIMÕES, R. F.; DINIZ, S. C. Urban Amenities and the Development of Creative Clusters: The Case of Brazil. Current Urban Studies, v. 1, n. 4, p. 92-101, 2013.

MARQUES, I. Cenas de um modernismo de província: Drummond e outros rapazes de Belo Horizonte. São Paulo: Ed. 34, 2011.

MARTINS, A. L. Revistas em revista: imprensa e práticas culturais em tempos de República, São Paulo (1890-1922). São Paulo: Edusp, 2008.

MAUAD, A. M. Na mira do olhar: um exercício de análise da fotografia nas revistas ilustradas cariocas, na primeira metade do século XX. Anais do Museu Paulista, São Paulo, v. 1, n.13, p. 133-176, 2005.

MINAS GERAIS. Anuário estatístico. Ano I (1921), v. IV. Belo Horizonte: Imprensa Oficial / Secretaria da Agricultura, 1926.

MINGOTI, S A. Análise de dados através de métodos de estatística multivariada. Belo Horizonte: Editora UFMG, 2007. 
MORAIS, F. Chatô, o rei do Brasil. São Paulo: Companhia das Letras, 1994.

MOREIRA, E. da L. Grupo Galpão: uma história de encontros. Belo Horizonte: Duo Editorial, 2010.

MOREIRA, L. da S. Imprensa periódica e vida política. In: RESENDE, M. E. L. de; VILLALTA, L. C. (Org.). História de Minas Gerais, v. 2. Belo Horizonte: Autêntica / Companhia do Tempo, 2013, p. 65-80.

MORETTIN, E. V. Humberto Mauro, cinema, história. São Paulo: Alameda Editorial, 2013.

MOTA, A. G. R. Divirta-se quem puder: história e lazer em Belo Horizonte através da revista Semana Illustrada, 1927-1928. Dissertação (Mestrado em Estudos do Lazer) - Universidade Federal de Minas Gerais Belo Horizonte, 2018.

MOURA, A. de P. Memória histórica da Escola Guignard. Belo Horizonte: Usina de Livros, 1993.

OLIVEIRA, R. C. S. de. As diversões em Diamantina: uma história registrada pela imprensa (1888-1915). Dissertação (Mestrado em Estudos do Lazer) - Universidade Federal de Minas Gerais Belo Horizonte, 2016.

ORTIZ, R. A moderna tradição brasileira: cultura brasileira e indústria cultural. 5. ed. São Paulo: Brasiliense, 1994.

PEREIRA, A. M. Traços de Belo Horizonte: a contribuição dos caricaturistas para a consolidação do modernismo na cidade. Dissertação (Mestrado em História) - Universidade Federal de Minas Gerais Belo Horizonte:, 2011.

PEREZ, L. F. Festas e viajantes nas Minas oitocentistas, segunda aproximação. Revista de Antropologia, São Paulo, v. 52, n. 1, p. 289-338, 2009.

RAMA, Á. A cidade das letras. São Paulo: Boitempo, 2015.

RIDENTI, M. Caleidoscópio da cultura brasileira (1964-2000). In: MICELI, Sergio; PONTES, Heloisa (Org.). Cultura e sociedade: Brasil e Argentina. São Paulo: Edusp, 2014, p. 21-72.

ROMERO, J. L. América Latina: as cidades e as ideias. Rio de Janeiro: Editora UFRJ, 2004.

ROSSI, M. S. Circulação e mediação da obra de arte na Belle Époque paulistana. Anais do Museu Paulista, São Paulo, v. 6/7, p. 83-119, 1998-1999.

SÁ, Carolina Mafra de. Meninas e moças casadouras nos palcos de São João del-Rei/MG: a educação das sensibilidades nos espetáculos realizados pelo Club Dramático Arthur Azevedo (1915-1916). Educação em Revista, v. 35, p. 1-29, 2019.

SANTAGATA, W. Cultural districts and their role in developed and developing countries. In: GINSBURGH, V. A.; THROSBY, D. (Org.). Handbook of the Economics of Arts and Culture. North-Holland, 2006.

SANTOS, A. C. dos et al. Editora Itatiaia: a velha guarda da edição nacional. In: MATARELLI, J.; QUEIROZ, S. (Org.). Editoras mineiras: panorama histórico. Belo Horizonte: Viva Voz, 2011, p. 39-47.

SIMIS, A. Estado e cinema no Brasil. São Paulo: Editora Unesp, 2015.

SINGER, P. Desenvolvimento econômico e evolução urbana. São Paulo: Editora Nacional, 1974.

VEAL, A. J. Economics of leisure. In: ROJEK, C.; SHAW, S. M.; VEAL, A. J. (Ed.). A handbook of leisure studies. New York: Palgrave Macmillan, 2006, p 140-161. 
VELLOSO, M. P. Os intelectuais e a política cultural do Estado Novo. In: FERREIRA, J.; DELGADO, L. de A. N. (Org.). O Brasil republicano: o tempo do nacional-estatismo, do início da década de 1930 ao apogeu do Estado Novo. v. 2. Rio de Janeiro: Civilização Brasileira, 2012, p. 145-180.

WERNECK, H. O desatino da rapaziada: jornalistas e escritores em Minas Gerais (1920-1970). 2. ed. São Paulo: Companhia das Letras, 2012.

WILLIAMS, D. Culture Wars in Brazil: The First Vargas Regime, 1930-1945. Durham/London: Duke University Press, 2001.

WIRTH, J. D. O fiel da balança: Minas Gerais na federação brasileira, 1889-1937. Rio de Janeiro: Paz e Terra, 1982.

XAVIER, R. D.; AMARAL, D. V. de O.; DIAS, C. Cultura, ferrovias e desenvolvimento econômico: circos em Minas Gerais no final do século 19. Revista de História Regional, v. 24, n. 1, p. 135-159, 2019.

\section{Sobre os autores}

CleberDias-cleberdiasufmg@gmail.com

Universidade Federal de Minas Gerais, Belo Horizonte, Minas Gerais, Brasil. ORCID: https://orcid.org/0000-0001-9126-5992.

Ana Flávia Machado - afmachad@cedeplar.ufmg.br

Universidade Federal de Minas Gerais, Belo Horizonte, Minas Gerais, Brasil. ORCID: https://orcid.org/0000-0001-8573-7906.

Vinicius Morais Silveira Hosken-vinicius.msh@hotmail.com

Universidade Federal de Minas Gerais, Belo Horizonte, Minas Gerais, Brasil. ORCID: https://orcid.org/0000-0002-4918-9356.

\section{Sobre 0 artigo}

Recebido em 28 de novembro de 2019. Aprovado em 17 de fevereiro de 2020. 


\section{APÊNDICE}

Tabela A1 Desvio padrão das variáveis selecionadas por clusters em 1920 e 2006-2010

\begin{tabular}{|c|c|c|c|c|c|c|c|c|c|c|}
\hline \multirow[t]{2}{*}{ Anos } & \multicolumn{5}{|r|}{1920} & \multicolumn{5}{|r|}{ 2006-2010 } \\
\hline & 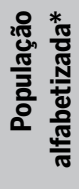 & 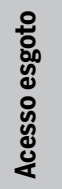 & 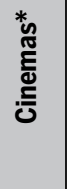 & 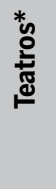 & 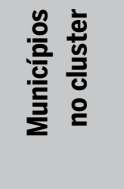 & 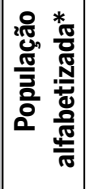 & 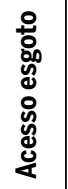 & 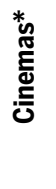 & 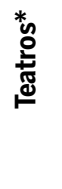 & 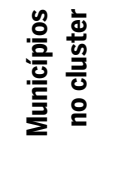 \\
\hline Cluster 1 & 0,13 & 0,30 & 0,69 & 1,11 & $7(4 \%)$ & & & & & $1(1 \%)$ \\
\hline Cluster 2 & 0,07 & 0,11 & 0,46 & 0,74 & $8(4 \%)$ & 0,02 & 0,08 & 2,88 & 2,80 & $104(58 \%)$ \\
\hline Cluster 3 & 0,07 & 0,09 & 0,77 & 0,81 & $41(23 \%)$ & 0,04 & 0,09 & 2,01 & 2,47 & $62(35 \%)$ \\
\hline Cluster 4 & 0,08 & 0,06 & 0,5 & 0,64 & $122(69 \%)$ & 0,05 & 0,06 & 0,40 & 1,17 & $11(6 \%)$ \\
\hline Total & & & & & $178(100 \%)$ & & & & & $178(100 \%)$ \\
\hline
\end{tabular}

Fonte: Brasil, 2010; Minas Gerais, 1926. Elaboração própria.

* Informações sobre os desvios-padrão se encontram no Anexo (Tabela A1). 